\title{
Allemands en Suisse: de loin pas encore des Suisses allemands
}

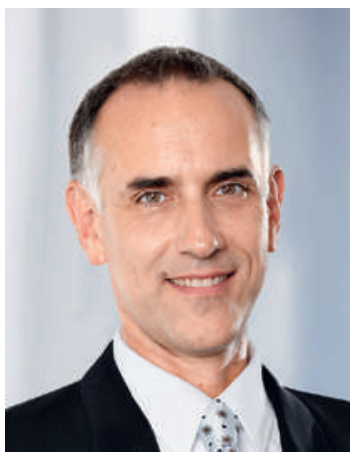

et aimable, m'était inconnue jusqu'ici.

En Suisse, l'usage veut que chacun dise son opinion puis qu'un consensus soit trouvé. Cela exige d'écouter et de laisser parler l'autre. Ce sont ainsi deux qualités que nous, Allemands, devons soit déjà posséder, soit très vite apprendre!

Selon la statistique médicale de la FMH 2011, le nombre de médecins exerçant en Suisse s'élève à 30849 [2] et selon la statistique 2010, 25\% des 30273 médecins recensés possèdent un diplôme de médecin étranger $(\mathrm{n}=7568)$, dont la majorité, $57 \%$, d'une université allemande [3]. Pour arrondir la statistique: à fin avril 2012, le nombre total d'étrangers vivant en Suisse était de 1789374 (22,6\% de la population globale) selon Avenir Suisse, dont 279672 Allemands, soit 11500 de plus qu'en 2011, sans compter les quelque 50000 frontaliers allemands. Par conséquent, la part des Allemands en Suisse s'élève à env. 3,5\% de la population globale.

Qu'est-ce qui rend la Suisse si appréciée des Allemands, au point d'y immigrer? Est-ce l'image adorable d'un petit pays propre en ordre, où les vaches broutent sur des montagnes en

\section{Petit versus grand: cette antinomie marque l'attitude des Suisses face aux Allemands.}

forme de Toblerone et où Heidi dévale en trombe des pistes de ski immaculées? Ces clichés sont bien ancrés dans les médias et dans la tête des gens, mais les facteurs d'attirance peuvent, outre le sentiment de proximité géographique et culturelle, être aussi la stabilité politique, le niveau élevé de la formation et de la recherche, la conscience écologique pour une nature intacte (si importante pour les loisirs), la confiance dans la place financière, et l'idée de partager la même langue.

La «vague allemande» ne se limite toutefois pas seulement au domaine de la santé mais elle touche aussi l'hôtellerie, l'administration et même les universités. Il n'en résulte pas seulement un ciel radieux, ... mais aussi un climat d'orage, car - comme le disait une conseillère nationale UDC à un journal de boulevard en avril dernier - ce ne sont pas les Allemands isolés qui la dérangent mais leur masse. Aussitôt après, l'institut de sondage Isopublic mena une enquête représentative auprès de mille personnes environ (hommes et femmes) en Suisse alémanique au sujet de l'immigration allemande dans notre pays [4]. Il s'avère que $64 \%$ de Suisses apprécient les Allemands qui vivent et travaillent ici. 36\% des personnes interrogées estiment la part des Allemands en Suisse trop élevée, 37\% d'entre elles limiteraient cette immigration si elles le pouvaient mais 58\% s'y opposent.

Les rapports des Suisses allemands avec le «grand canton» limitrophe du nord sont également marqués par la relation traditionnelle entre un petit et un grand: le petit reproche au grand d'être froid, arrogant et matérialiste tout en s'estimant chaleureux, modeste et idéaliste. En Suisse, on fait générale-

\section{Malgré la concurrence sur le marché de l'emploi et du logement, les Allemands contribuent à la qualité des soins en faveur de la population suisse.}

ment preuve de beaucoup de respect et d'une grande d'empathie. C'est peut-être la raison pour laquelle les immigrants assimilent le tempérament fondamental des Suisses et deviennent plus retenus et plus modestes.

Enfin, bien que les Allemands soient des concurrents sur le marché de l'emploi et du logement, n'oublions pas, en ce qui concerne la santé, que les médecins et le personnel soignant allemands fournissent une contribution précieuse à l'encadrement médical et infirmier de la population.

Aujourd'hui, je peux répondre à Gian: «Danke, es goht guet ond mer isch wohl» [5].

\section{Dr Gert Printzen, double national suisse et allemand,} membre du Comité central

\section{Références}

1 «Bonjour, comment ça va? Je m'appelle Gian et je suis ton médecin-chef. On se tutoie!»

2 Kraft E. 30849 médecins au service de la Suisse. Bull Méd Suisses. 2012; 93(11):399-403.

3 Kraft E, Hersperger M. Les soins médicaux en Suisse sont aussi garantis grâce aux femmes et aux médecins étrangers. Bull Méd Suisses. 2011;92(49):1899-1901.

4 Das Image der Deutschen in der Schweiz. Gallup TELEOmnibus: Befragung vom 25.-28. April 2012. Isopublic Projekt: $612,28.4 .2012$.

5 «Merci, tout va pour le mieux et je me sens bien!» 